\title{
Knockout of ERKI Enhances Cocaine-Evoked Immediate Early Gene Expression and Behavioral Plasticity
}

\author{
Susan M Ferguson', Stefania Fasano ${ }^{2,3}$, Pengwei Yang ${ }^{4}$, Riccardo Brambilla ${ }^{2}$ and Terry E Robinson*,1,4 \\ 'Neuroscience Program, University of Michigan, Ann Arbor, MI, USA; ${ }^{2}$ San Raffaele Research Institute and University, Milano, Italy; ${ }^{3}$ Istituto di \\ Psicologia, Facoltà di Medicina, Università degli Studi di Milano, Milano, Italy; ${ }^{4}$ Department of Psychology, University of Michigan, Ann Arbor, \\ MI, USA
}

\begin{abstract}
The ability of cocaine to produce lasting neural adaptations in mesocorticolimbic brain regions is thought to promote drug seeking and facilitate addiction in humans. The Ras-controlled Raf-MEK-ERK protein kinase signaling cascade has been implicated in the behavioral and neurobiological actions of cocaine in animals. However, these pharmacological studies have not been able to determine the specific role of the two predominant isoforms of ERK (ERKI and ERK2) in these processes. We report here that deletion of the ERKI isoform, which leads to increased ERK2 stimulus-dependent signaling, facilitates the development of cocaine-induced psychomotor sensitization and the acquisition of a cocaine conditioned place preference. Conversely, pharmacological blockade of ERK signaling attenuates the development of psychomotor sensitization to cocaine. Finally, cocaine-evoked gene expression in mesocorticolimbic brain regions is potentiated in ERKI-deficient mice. Thus, alterations in ERK signaling influence both the neurobiological impact of cocaine and its ability to produce enduring forms of drug experience-dependent behavioral plasticity. Our results suggest that enhanced ERK2 signaling following repeated drug exposure may facilitate the development of forms of cocaine-induced plasticity that contribute to addiction. Neuropsychopharmacology (2006) 3 I, 2660-2668. doi: I 0. I038/sj.npp. I 30 I 0 I4; published online I I January 2006
\end{abstract}

Keywords: dopamine; psychostimulants; glutamate; striatum; in situ hybridization; mouse

\section{INTRODUCTION}

Repeated exposure to drugs of abuse, including cocaine, produces a complex reorganization of dopamine-rich brain regions associated with reward and incentive motivation, such as the striatum (ie nucleus accumbens and caudateputamen) - which in turn is thought to promote drugseeking behavior and facilitate the transition to addiction in humans (Robinson and Berridge, 2000; Everitt et al, 2001; Hyman and Malenka, 2001; Nestler, 2001). In laboratory animals, drug-induced neuroadaptations have been associated with various types of behavioral plasticity, such as psychomotor sensitization and conditioned place preference (Robinson and Berridge, 1993, 2000). Importantly, the same brain regions implicated in maladaptive responses to addictive drugs are also essential for various forms of cognitive processing, including motor programming, habit learning and instrumental conditioning (Berke and Hyman, 2000; Hyman and Malenka, 2001; Fasano and Brambilla,

*Correspondence: Dr TE Robinson, Department of Psychology (Biopsychology), University of Michigan, East Hall, 525 East University Avenue, Ann Arbor, MI 48 I 09- I 109, USA, Tel: 734763 I304, Fax: 734 763 7480,E-mail: ter@umich.edu

Received 26 May 2005; revised 18 November 2005; accepted 21 November 2005

Online publication: 25 November 2005 at http://www.acnp.org/ citations/Npp | | 2505050350/default.pdf
2002; Packard and Knowlton, 2002; Chao and Nestler, 2004). Nonetheless, relationships between these different types of behavioral plasticity, and the ways in which they mechanistically interact, remain unclear. Elucidating the molecular mechanisms that underlie these forms of persistent drug experience-dependent plasticity should help to illuminate the critical steps that mark the transition to addiction.

The Ras-controlled Raf-MEK-ERK protein kinase signaling cascade has been identified as an important mediator of both cognitive processing and the neurobiological effects of psychostimulant drugs, suggesting that this pathway may be essential for both experience- and drug-dependent neural adaptations (Orban et al, 1999; Fasano and Brambilla, 2002). For example, pharmacological inhibition of MEK, the upstream activator of the two major ERK isoforms in the brain (ERK1 and ERK2), prevents both hippocampus- and amygdala-dependent memory formation (Atkins et al, 1998; Schafe et al, 1999; Adams and Sweatt, 2002). Pharmacological blockade of the Raf-MEK-ERK cascade also attenuates the development of a conditioned place preference to cocaine, amphetamine or MDMA (Valjent et al, 2000; Salzmann et al, 2003; Gerdjikov et al, 2004) and appears to modulate the development of psychomotor sensitization to cocaine (Pierce et al, 1999; Valjent et al, 2005). In addition, administration of psychomotor stimulant drugs increases ERK activity in several mesocorticolimbic brain regions associated with drug addiction (Valjent et al, 2000, 2005; 
Adams et al, 2001; Choe et al, 2002; Choe and Wang, 2002) and the induction of immediate early genes (IEGs) in these brain regions is largely attenuated by pharmacological blockade of this pathway (Valjent et al, 2000; Salzmann et al, 2003; Ferguson and Robinson, 2004).

Nonetheless, MEK inhibitors such as U0126 or SL327 do not discriminate between ERK1 and ERK2, and therefore are not suitable tools to investigate the specific role of these two major ERK isoforms. Evidence from a mouse strain in which the ERK1 gene has been deleted has provided clear support for a differential role for ERK1 and ERK2 in cell signaling, memory formation, and responsitivity to morphine (Pages et al, 1999; Mazzucchelli et al, 2002). In these mice, loss of ERK1 results in stimulus-dependent enhancement of ERK2-dependent signaling in a variety of cell types, including primary neurons and fibroblasts in culture. This phenotype is thought to be due to a differential ability of ERK1 and ERK2 in transducing downstream signaling, whereby ERK2 is thought to be a more efficient kinase and ERK1 is believed to act as a partial agonist (Vantaggiato et al, 2006). Thus, in the absence of ERK1, ERK2 is able to interact with the upstream kinase MEK more efficiently resulting in a stronger signaling output. Accordingly, synaptic plasticity in the striatum, but not other structures such as the hippocampus or the amygdala, is enhanced in ERK1-deficient mice. Consequently, ERK1-deficient mice show enhanced memory formation in striatum-dependent learning tests and an increased conditioned place preference to morphine (Mazzucchelli et al, 2002). Using this mouse model of striatum-dependent neuronal plasticity, the present study sought to characterize some of the behavioral and molecular responses to cocaine.

\section{METHODS}

\section{Subjects}

Male ERK1 mutant and wild-type mice aged 11-19 weeks at the start of the experiment were housed 2-4 per cage. ERK1 mutant and wild-type mice were generated as described previously (Pages et al, 1999), and the mice used in the experiments were F2 littermates from C57BL/6 mice that were backcrossed to $129 / \mathrm{SvJ}$ mice for one generation. For the pharmacological blockade experiment, male C57/BL6 mice were purchased from Harlan Sprague Dawley (Indianapolis, IN). The mice were aged 7 weeks at the start of the experiment and were housed 3-4 per cage. The animal facilities were temperature- and humidity-controlled and maintained on a $14: 10 \mathrm{~h}$ light: dark cycle, with food and water available ad libitum. All experimental procedures were approved by local committees (the University of Michigan Committee on the Use and Care of Animals and the San Raffaele Institute IACUC).

\section{Drugs}

Cocaine was dissolved in sterile $0.9 \%$ saline. SL327 (generously donated by Bristol-Myers-Squibb, Wilmington, DE, USA), an inhibitor of MEK (the dual-specific protein kinase that phosphorylates ERK), was dissolved in $25 \%$ DMSO (diluted twice in sterile water). All drugs were administered by intraperitoneal (i.p.) injection in a volume of $10 \mathrm{ml} / \mathrm{kg}$. SL327 was chosen because it crosses the bloodbrain barrier and is highly selective for MEK over other kinases. It has an IC50 of $180 \mathrm{nM}$ for MEK1 and $220 \mathrm{nM}$ for MEK2 (Favata et al, 1998). The dose of SL327 used in the present study $(40 \mathrm{mg} / \mathrm{kg})$ was chosen because it has been shown to effectively block ERK activation in vivo (Selcher et al, 1999) and we have found it to be effective at reducing psychostimulant-evoked IEG expression without altering the acute locomotor activating effects of psychostimulants (Ferguson and Robinson, 2004 and data not shown).

\section{Psychomotor Sensitization}

The psychomotor activating effects of cocaine were measured using locomotor activity boxes $(8.5 \times 17.5 \times 9$ inch $)$ that contained a clear plastic insert in the center of the cage $(2.5 \times 9 \times 9$ inch $)$ and ground corncob bedding on the floor. Two experiments were conducted. One, the effect of pharmacological blockade of ERK signaling on cocaine psychomotor sensitization in C57/ BL6 mice was evaluated. Second, the effect of ERK1 deletion on cocaine psychomotor sensitization was determined. All mice received seven injections of cocaine $(15 \mathrm{mg} / \mathrm{kg})$ or saline over a 2-week treatment period (one injection every other day). For the MEK inhibitor experiment, one hour prior to testing C57/BL6 mice received an injection of $25 \%$ DMSO (diluted twice in sterile water) or SL327 (40 mg/kg), a highly selective inhibitor of the ERK kinase MEK, and were placed back into their home cage. For the experiment with ERK1 mutants, mice received a $1 \mathrm{~h}$ habituation period prior to each injection. Behavior was recorded for $60 \mathrm{~min}$ during each test session.

For the MEK inhibitor experiment, following a 2-week withdrawal period mice received an escalating dose challenge of cocaine $(0,5,10$, and $20 \mathrm{mg} / \mathrm{kg})$ in the absence of SL327 pretreatment. For this challenge test, all mice were given a $1 \mathrm{~h}$ habituation period to the test cage, followed by four injections spaced one hour apart. Behavior was recorded for $5 \mathrm{~h}$. Locomotor activity was used as an index of psychomotor sensitization and was assessed by the number of cage crossovers.

\section{Conditioned Place Preference}

The rewarding effects of cocaine were measured using a conditioned place preference procedure with an unbiased, three-phase design (pre-conditioning, conditioning and post-conditioning) as described previously (Maldonado et al, 1997). Briefly, during the pre-conditioning phase mice were allowed $18 \mathrm{~min}$ free access to a three-chamber conditioned place preference apparatus (containing two large compartments separated by a central neutral area). The compartments differed in floor texture and wall pattern. Two mice from each genotype spent more than $75 \%$ of their time in any one compartment and were discarded from the study. During the conditioning phase mice received three pairings with cocaine $(10 \mathrm{mg} / \mathrm{kg})$ in one chamber and three pairings with saline in the other (one pairing per day for six consecutive days). Saline-treated mice received six pairings of saline. Immediately following each injection mice were confined to a given chamber for 20 min. During the post-conditioning phase mice were given 
$18 \mathrm{~min}$ free access to a conditioned place preference apparatus $24 \mathrm{~h}$ following the final conditioning trial. A place preference score was calculated for each mouse as the difference between pre-conditioning and post-conditioning time spent in the drug-paired compartment.

\section{In Situ Hybridization}

Following a $1 \mathrm{~h}$ habituation period in the locomotor activity boxes, ERK1 mutant and wild-type mice received an injection of saline or cocaine $(15 \mathrm{mg} / \mathrm{kg})$. Fifty minutes later animals were decapitated and their brains removed, frozen in isopentane and stored at $-70^{\circ} \mathrm{C}$. Coronal brain sections $(16 \mu \mathrm{m})$ were cut on a cryostat, thaw-mounted onto Superfrost/Plus slides (Fisher Scientific, Pittsburgh, PA) and stored at $-70^{\circ} \mathrm{C}$ until processed for in situ hybridization. Slides containing four tissue sections were processed using a ${ }^{35}$ S-UTP- and -CTP-labeled riboprobe complementary to c-fos mRNA (680-mer, courtesy of Dr T Curran, St Jude Children's Research Hospital, Memphis, TN) and a digoxigenin-UTP labeled riboprobe complementary to preproenkephalin mRNA (693-mer, courtesy of Dr J Douglass, Amgen, Thousand Oaks, CA) according to a modified version of a protocol by Curran and Watson (1995) that is described in detail by Ferguson and Robinson (2004).

\section{Quantification and Analysis of Gene Expression}

Slides were exposed to X-ray film for 7 days (Kodak Biomax MR, Rochester, NY) and then dipped in emulsion (Ilford KD-5, Polysciences, Warrington, PA) and stored in light tight boxes at $4{ }^{\circ} \mathrm{C}$ for 21 days. Initial quantification of $\mathrm{c}-\mathrm{fos}$ mRNA (c-fos) expression was conducted on autoradiographs across the rostrocaudal extent of the dorsomedial portion of the caudate-putamen and the cingulate, a region of cortex that densely innervates the dorsomedial caudateputamen (McGeorge and Faull, 1989; Willuhn et al, 2003; Paxinos and Franklin, 2004). Sections were quantified as described previously (Badiani et al, 1998). Integrated density measurements indicated that the difference in cocaine-evoked c-fos expression between ERK1 mutant and wild-type mice appeared greatest in the caudateputamen on sections $0.4 \mathrm{~mm}$ anterior to bregma. This region was therefore selected for further analysis of cell phenotype.

The majority of cells in the caudate-putamen are medium spiny projection neurons that either co-express mRNA for dopamine D2 receptors and preproenkephalin and are part of the striatopallidal pathway (these will be called Enk + or striatopallidal cells) or co-express mRNA for dopamine D1 receptors, preprodynorphin and preprotachykinin (but not preproenkephalin) and are part of the striatonigral pathway (these will be called Enk- or striatonigral cells). The number of single- and double-labeled cells in the dorsomedial caudate-putamen containing c-fos mRNA (c-fos +$)$ and/ or preproenkephalin mRNA $(\mathrm{Enk}+)$ was counted in three $250 \mu \mathrm{m}^{2}$ grids in each hemisphere (for a total area of $1.5 \mathrm{~mm}^{2}$ ) using a Leica microscope (Letiz DMR, Wetzler, Germany) at $\times 20$ magnification. We have found that under our in situ conditions all psychostimulant-evoked c-fos + cells are either co-labeled with preproenkephalin mRNA or preprodynorphin/preprotachykinin mRNA. Therefore, in the present study the number of c-fos/Enk + cells was subtracted from the total number of c-fos + cells in the caudate-putamen for each animal to give the number of $\mathrm{c}$ fos/Enk - cells. This number was then used as an indication of the number of cells in the striatonigral pathway that were activated following each treatment. Finally, the number of cfos positive cells in the nucleus accumbens core and shell at level $1.2 \mathrm{~mm}$ anterior to bregma was counted in one $250 \mu \mathrm{m}^{2}$ grid in each hemisphere per region (for a total area of $0.5 \mathrm{~mm}^{2} /$ region). ${ }^{35}$ S-labeled cells (containing c-fos) appeared as dense clusters of silver grains under darkfield conditions and digoxigenin-labeled cells (containing preproenkephalin mRNA) appeared as purple precipitates under brightfield conditions (see Figure 4). The number of preproenkephalin mRNA positive cells did not differ across groups (data not shown).

\section{RESULTS}

\section{Inhibiton of MEK Attenuates Cocaine Psychomotor Sensitization}

The role of ERK signaling in psychomotor sensitization to cocaine has not been fully characterized. Therefore, prior to conducting sensitization experiments in the ERK1 mutant mice, the effect of pharmacological blockade of the ERK signaling cascade on psychomotor sensitization in wild-type mice was evaluated (Figure 1).

Treatment phase. Treatment with the MEK inhibitor SL327 had no effect on the acute locomotor-activating effects of cocaine (or on behavior in animals given saline), and no effect on the increase in locomotor activity (sensitization) seen in both groups with repeated administration of cocaine (Figure 1a; main effect of test session; $\mathrm{F}_{1,17}=48.03$, $p<0.0001$; Bonferroni's post hoc, $p<0.001$; main effect of antagonist pretreatment and interaction between antagonist pretreatment, and test session factors not significant; $\left.\mathrm{F}_{1,17}=0.05-1.54, p=0.18-0.87\right)$ during this phase of the experiment.

Challenge phase. Figure 1 (panels $\mathrm{b}$ and $\mathrm{c}$ ) shows the locomotor response to a multiple-dose challenge of cocaine $(0,5,10$, and $20 \mathrm{mg} / \mathrm{kg})$ administered 14 days following the last (7th) treatment injection. Note that SL327 was not administered on this challenge test session, but this test was conducted to determine the effect of past exposure to cocaine, with or without co-treatment with SL327. At the two lowest challenge doses tested ( 5 and $10 \mathrm{mg} / \mathrm{kg}$ ), two-way ANOVAs on each challenge dose resulted in significant interactions between antagonist pretreatment and drug treatment factors (Figure $1 \mathrm{~b} ; \mathrm{F}_{1,38}=5.73-16.96, p=0.02-$ 0.0002). Bonferroni's post hoc tests showed that at these two challenge doses there were no differences between salinepretreated groups (Figure $1 \mathrm{~b} ; p>0.05$ ), but there were significant differences between cocaine-pretreated groups (Figure $1 \mathrm{~b} ; p<0.05$ ) due to an increase in the locomotor response of cocaine-pretreated animals that had also received DMSO pretreatment. Thus, animals that received SL327 during the treatment phase did not exhibit sensitization when challenged with these doses of cocaine. A 

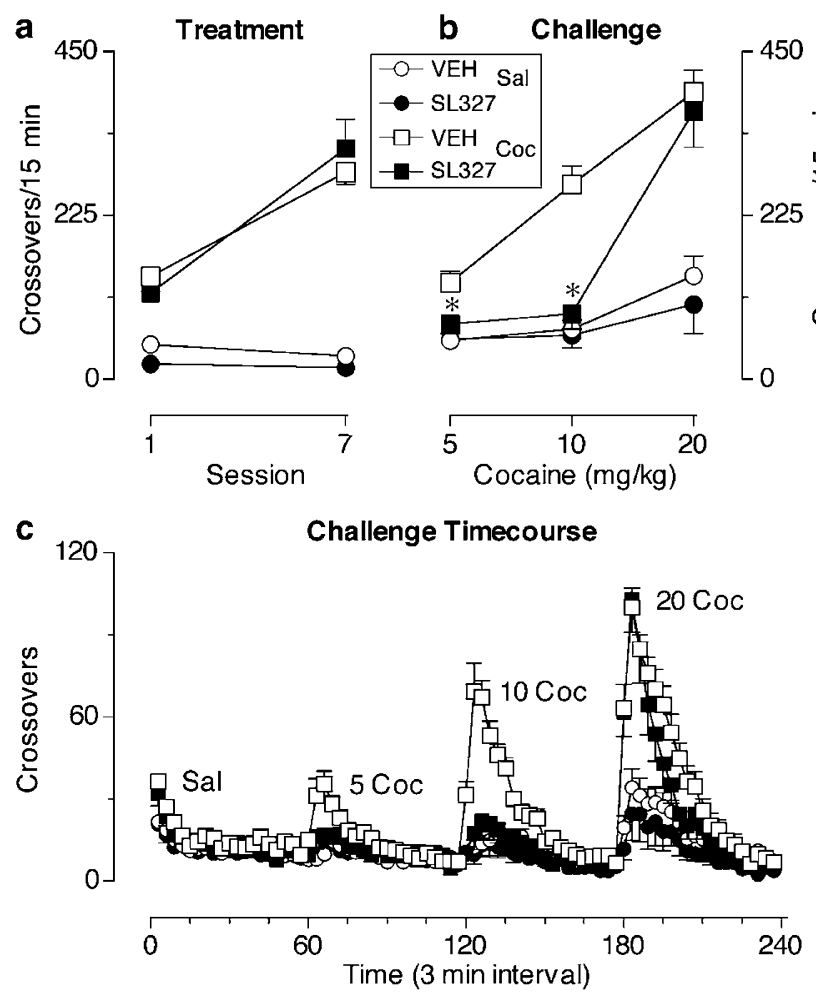

Figure I The MEK inhibitor SL327 attenuates the development of psychomotor sensitization to cocaine. (a) Treatment phase: The mean $( \pm S E M)$ number of crossovers made during the first 15 min following saline treatment (circles) or cocaine treatment (squares). White symbols represent groups co-administered DMSO vehicle (VEH) and black symbols groups co-administered SL327. (b) Challenge Phase: The mean ( \pm SEM) number of crossovers made during the first $15 \mathrm{~min}$ following each dose of a multiple-dose challenge (injections spaced I h apart), when SL327 was not administered. (c) The mean ( \pm SEM) number of crossovers over time (3min intervals) during the multiple-dose challenge test. *, differs from the DMSO vehicle-cocaine treatment group $(p<0.05$, two-way ANOVA, Bonferroni's test). $N=7-15$ /group.

sensitized response was revealed in animals previously treated with SL327, but only at the highest dose tested $(20 \mathrm{mg} / \mathrm{kg}$ ) (Figure $1 \mathrm{~b}$; main effect of drug treatment; $\mathrm{F}_{1,38}=52.21, p<0.0001$; main effect of antagonist pretreatment and interaction between antagonist pretreatment and drug treatment factors not significant; $F_{1,38}=0.03-0.85$, $p=0.36-0.86)$. These data confirm and extend previous reports indicating that pharmacological blockade of ERK signaling attenuates, but does not entirely block, the development of psychomotor sensitization.

\section{ERK1 Mutant Mice Show Enhanced Cocaine Psychomotor Sensitization}

Figure 2 shows the development of psychomotor sensitization to cocaine in wild-type and ERK1 mutant mice. A twoway ANOVA with repeated measures on one factor resulted in a significant main effect of Genotype (Figure 2a; $\left.\mathrm{F}_{1,11}=13.40, p=0.03\right)$, a significant main effect of test session (Figure $2 \mathrm{a} ; \mathrm{F}_{1,11}=37.69, p=0.0005$ ) and a significant genotype by test session interaction (Figure 2a; $\left.\mathrm{F}_{1,11}=8.42, p=0.04\right)$. Bonferroni's post hoc tests showed that there was no difference between wild-type and ERK1

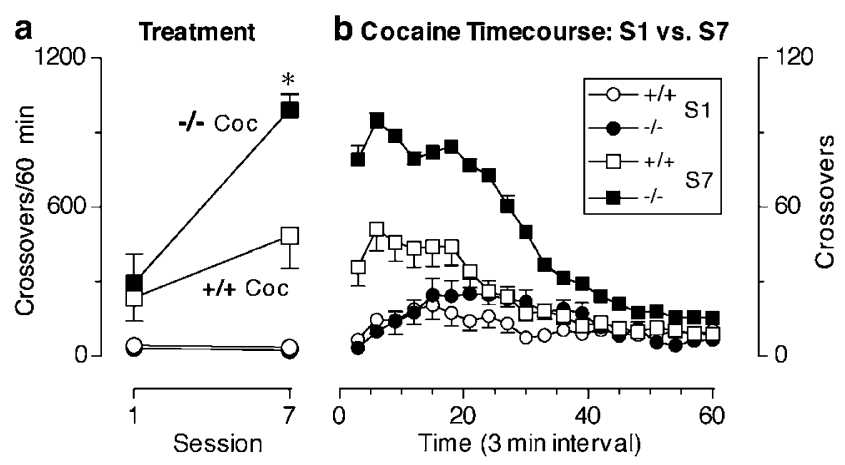

Figure 2 Cocaine psychomotor sensitization is enhanced in ERKI mutant mice. (a) The mean ( \pm SEM) number of crossovers made during the $60 \mathrm{~min}$ following saline treatment (circles) or cocaine treatment (squares). White symbols represent wild-type groups $(+/+)$ and black symbols represent ERKI mutant groups $(-/-)$. (b) The mean ( \pm SEM) number of crossovers over time (3-min intervals) on test session I (circles) and on test session 7 (squares) for the cocaine-treated groups. White symbols represent the wild-type group $(+/+)$ and black symbols represent the ERKI mutant group $(-/-)$. *, differs from the cocainetreated wild-type group $(p<0.05$, two-way repeated measures ANOVA, Bonferroni's test). $N=6-7 /$ group.

mutant mice treated with cocaine on test session 1 (Figure $2 \mathrm{a} ; p>0.05$ ), but there was a significant difference between wild-type and ERK1 mutant mice treated with cocaine on test session 7 (Figure 2a; $p<0.05$ ), indicating that ERK1 mutant mice sensitized to a greater extent than wild-type controls. Figure 2 (panel b) illustrates the time course of the effect of cocaine on locomotor activity in wildtype and ERK1 mutant mice during test session $1 v s$ test session 7 .

\section{ERK1 Mutant Mice Show Enhanced Conditioned Place Preference to Cocaine}

The rewarding effects of cocaine were assessed in ERK1 mutant mice using a conditioned place preference procedure (Figure 3). Two-way analyses of variance (ANOVA) revealed a significant effect of drug treatment $\left(\mathrm{F}_{1,34}=63.92\right.$, $p<0.0001)$, a significant effect of genotype $\left(\mathrm{F}_{1,34}=3.64\right.$, $p=0.03)$ and a significant drug treatment by genotype interaction $\left(\mathrm{F}_{1,34}=7.95, p=0.002\right)$. Bonferroni's post hoc tests showed that both wild-type and ERK1 mutant mice developed a significant conditioned place preference $(p<0.001)$. However, a more robust preference for the cocaine-paired environment was seen in ERK1 mutants in comparison to wild-type mice $(p<0.001)$. Thus, the results from the sensitization and conditioned place preference experiments demonstrate that loss of ERK1 facilitates cocaine-mediated responses, in striking contrast to what is seen in the presence of the MEK inhibitor SL327.

\section{ERK1 Mutant Mice Show Enhanced Cocaine-Evoked IEG Expression}

Next, we sought to determine whether ERK1-deficient mice also showed alterations in IEG expression in relevant brain regions. Figure 4 (panel a) shows representative autoradiographs of cocaine-evoked c-fos expression in wild-type and ERK1 mutant mice. 


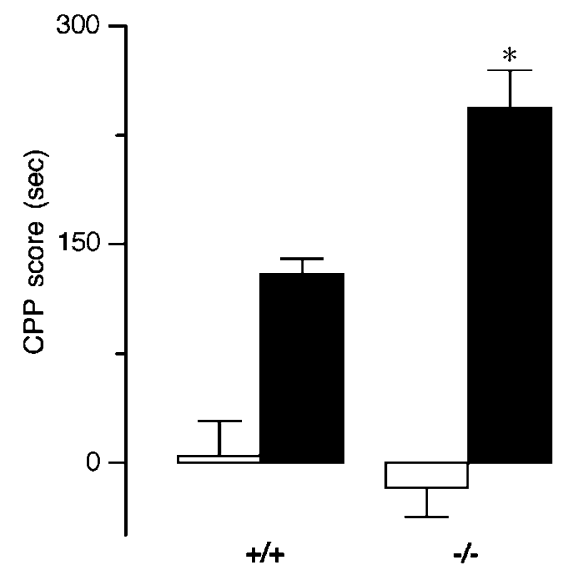

Figure 3 The rewarding effects of cocaine are enhanced in ERKI mutant mice, as demonstrated in a conditioned place preference paradigm. Data represent the mean $( \pm S E M)$ conditioned place preference score, calculated as the difference between pre-conditioning and post-conditioning time spent in the drug-paired compartment. White bars represent groups receiving only saline pairings during conditioning and black bars represent groups receiving saline and cocaine pairings during conditioning. $(+/+)$ represents wild-type groups and $(-/-)$ represents ERKI mutant groups. *, differs from the wild-type group receiving cocaine conditioning ( $p<0.05$, Two-way ANOVA, Bonferroni's test). $N=8-12 /$ group.
Caudate-putamen. Cocaine induced significantly more cfos expression across the rostral-caudal extent of the dorsomedial caudate-putamen compared to saline (Figure 4b; main effect of drug treatment at each level quantified, $\left.\mathrm{F}_{1,27}=17.98-31.67, p=0.0002-0.01\right)$. At most levels, two-way ANOVAs resulted in significant interactions between genotype and drug treatment factors (Figure $4 \mathrm{~b}$; $\left.\mathrm{F}_{1,27}=8.3-9.4, p=0.025-0.05\right)$. Bonferroni's post hoc tests showed that there were no differences between wild-type and ERK1 mutant mice treated with saline (Figure 4b; $p>0.05$ ), but there were significant differences between wild-type and ERK1 mutant mice treated with cocaine (Figure $4 \mathrm{~b} ; p<0.01$ ), due to a greater cocaine-evoked c-fos response in the dorsomedial caudate-putamen of ERK1 mutant mice.

The effect of Genotype appeared greatest at level $0.45 \mathrm{~mm}$ anterior to bregma, and therefore the number of c-fos/Enk + and c-fos/Enk - cells was analyzed at this level. Figure 4 (panel d) provides representative examples of a c-fos/Enk + dual in situ. Cocaine significantly increased the number of c-fos/Enk + cells and the number of c-fos/Enk- cells compared to saline (data not shown; main effect of drug for each cell type, $\left.\mathrm{F}_{1,27}=38.02-59.84, p<0.0001\right)$. There was a significant interaction in the number of c-fos/Enk + cells between genotype and drug treatment factors $\left(\mathrm{F}_{1,27}=8.51\right.$, a
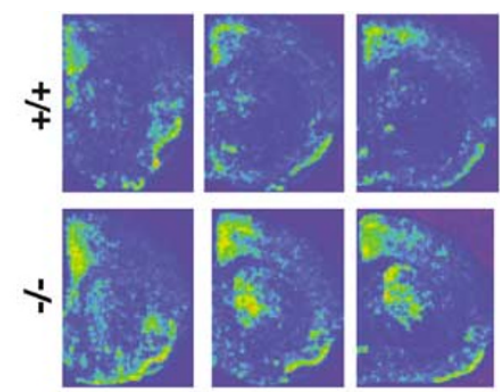

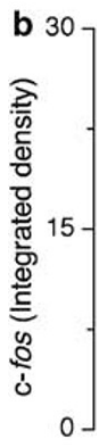
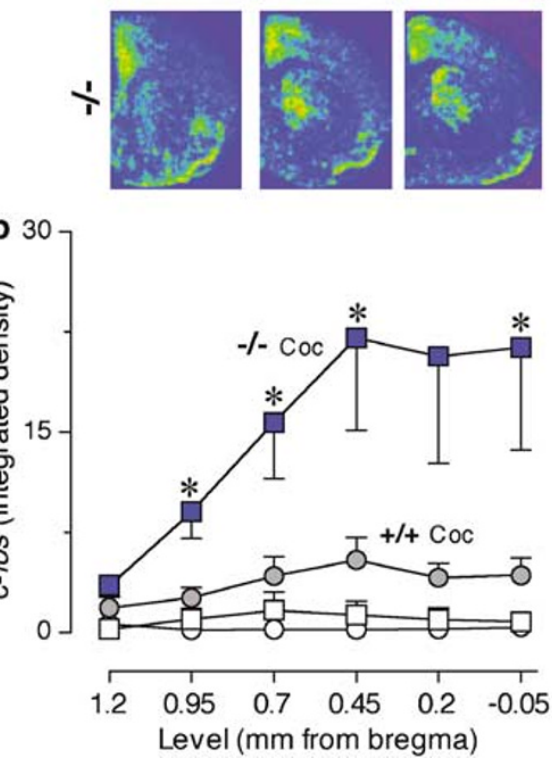

c

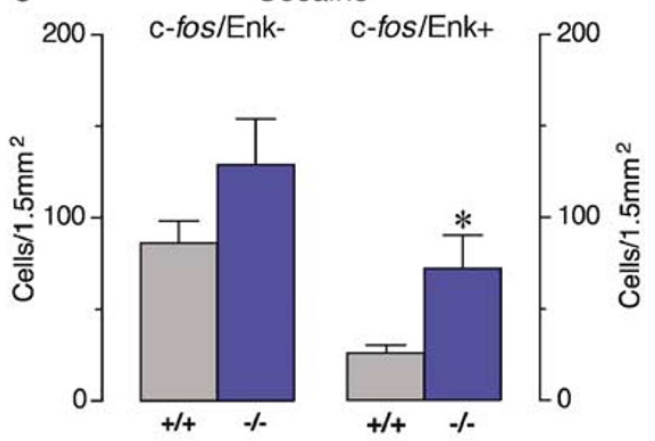

d

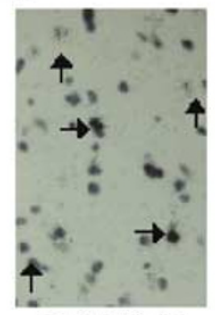

Brightfield

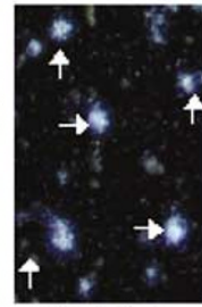

Darkfield

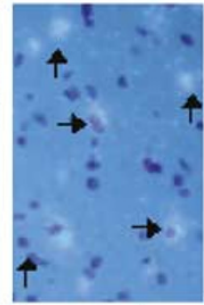

Combination

Figure 4 The neurobiological impact of cocaine is enhanced in the caudate-putamen of ERKI mutant mice. (a) Representative autoradiographs of cocaine-evoked c-fos mRNA (c-fos) expression in wild-type (top panels) and ERKI mutant mice (bottom panels). (b) Mean ( \pm SEM) c-fos expression (integrated density) across the rostral-caudal extent of the dorsomedial caudate-putamen. Circles represent wild-type groups $(+/+)$ and squares represent ERKI mutant groups $(-/-)$. Filled symbols represent cocaine-treated groups and open symbols represent saline-treated groups. (c) The mean ( \pm SEM) number of cocaine-evoked c-fos/Enk - cells (left panel) and c-fos/Enk + cells (right panel) at level $0.45 \mathrm{~mm}$ anterior to bregma. Gray bars represent wild-type mice and blue bars represent ERKI mutant mice. (d) Representative histological plates depicting sections from the dorsomedial caudate-putamen that were doubled-labeled for c-fos mRNA and preproenkephalin mRNA. Sections were taken from an ERKI mutant mouse that received cocaine (I5 mg/kg). (Left) Brightfield image in which Enk + cells are indicated by purple precipitate. (Middle) Darkfield image in which c-fos + cells are indicated by clusters of silver grains. (Right) Overlay of brightfield and darkfield images. Up arrows indicate single-labeled cells (c-fos + or Enk + ). Right arrows indicate double-labeled cells (c-fos/Enk + ). *, differs from the cocaine-treated wild-type group ( $p<0.05$, two-way ANOVA, Bonferroni's test). $N=7-9 / g r o u p$. 
$p=0.03)$. Bonferroni's post hoc tests showed that there was no difference in the number of c-fos/Enk + cells between saline groups (data not shown; $p>0.05$ ), but there was a significant difference between wild-type and ERK1 mutant mice treated with cocaine (Figure 4c; $p<0.01$ ), due to a three-fold increase in the number of cocaine-evoked c-fos/ Enk + cells in ERK1 mutant mice. In contrast, there was no effect of genotype on the number of saline- or cocaineevoked c-fos/Enk - cells (Figure 4c for cocaine groups, data not shown for saline groups; interaction between genotype and drug treatment factors not significant, $F_{1,27}=2.37$, $p=0.18)$.

Nucleus accumbens. Cocaine significantly increased the number of c-fos + cells in the nucleus accumbens shell (Figure 5a) compared to saline (main effect of Drug, $\mathrm{F}_{1,27}=12.89, p=0.0013$ ). There was a significant interaction in the number of c-fos + cells between genotype and drug treatment factors $\left(\mathrm{F}_{1,27}=4.92, p=0.035\right)$. Bonferroni's post hoc tests showed that there was no difference in the number of c-fos + cells between saline groups $(p>0.05)$, but there was a significant difference between wild-type and ERK1 mutant mice treated with cocaine $(p<0.05)$, due to an increase in the number of cocaine-evoked c-fos + cells in ERK1 mutant mice.

Cocaine also significantly increased the number of c-fos + cells in the nucleus accumbens core (Figure 5b) compared to saline (main effect of Drug, $F_{1,27}=46.25, p<0.0001$ ). Although there was also a significant main effect of Genotype $\left(\mathrm{F}_{1,27}=5.05, p=0.03\right)$, the interaction between genotype and drug treatment factors did not quite reach statistical significance $\left(\left(\mathrm{F}_{1,27}=3.31, p=0.08\right)\right.$, Bonferroni's post hoc tests showed that there was no difference in the number of $c-f o s+$ cells between saline groups $(p>0.05)$, but there was a significant difference between wild-type and ERK1 mutant mice treated with cocaine $(p<0.05)$, due to an increase in the number of cocaine-evoked c-fos + cells in ERK1 mutant mice.

Cingulate cortex. Figure 6 shows saline- and cocaineinduced c-fos expression in the cingulate cortex of wild-type and ERK1 mutant mice. At most levels $(0.7$ to -0.05 relative to bregma), two-way ANOVAs resulted in significant interactions between genotype and drug treatment factors $\left(\mathrm{F}_{1,27}=12.06-25.49, p<0.001-p=0.04\right)$. Bonferroni's post hoc tests showed that there were no differences in c-fos expression between wild-type and ERK1 mutant mice treated with saline $(p>0.05)$, but there were significant differences between wild-type and ERK1 mutant mice treated with cocaine $(p=0.0005-p<0.05)$, due to a increase in c-fos expression above control levels only in ERK1 mutant mice.

\section{DISCUSSION}

The Ras-controlled Raf-MEK-ERK protein kinase signaling cascade is known to play a critical role in the development of neuronal plasticity (English and Sweatt, 1996, 1997; Martin et al, 1997) and long-term memory formation (Atkins et al, 1998; Orban et al, 1999; Adams and Sweatt, 2002). Changes in ERK signaling have also been associated
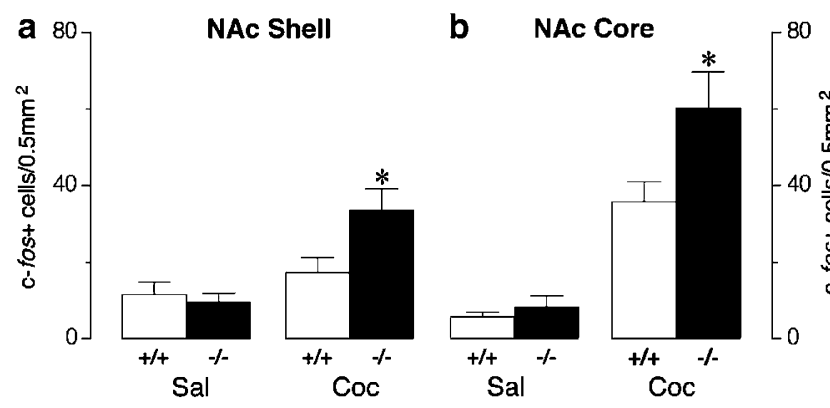

Figure 5 The neurobiological impact of cocaine is enhanced in the nucleus accumbens of ERKI mutant mice. (a) The mean ( \pm SEM) number of saline-evoked (left panel) or cocaine-evoked (right panel) c-fos + cells in the nucleus accumbens shell at level $1.2 \mathrm{~mm}$ anterior to bregma. (b) The mean $( \pm S E M)$ number of saline-evoked (left panel) or cocaine-evoked (right panel) c-fos + cells in the nucleus accumbens core at level $1.2 \mathrm{~mm}$ anterior to bregma. White bars represent wild-type groups $(+/+)$ and black bars represent ERKI mutant groups $(-1-)$. *, differs from the cocaine-treated wild-type group ( $p<0.05$, two-way ANOVA, Bonferroni's test). $N=7-9 /$ group

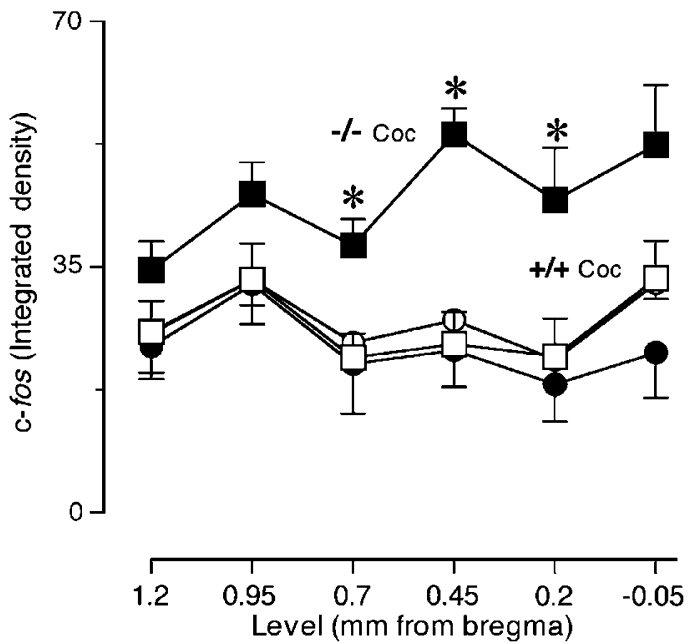

Figure 6 The neurobiological impact of cocaine is altered in the cortex of ERKI mutant mice. Mean ( \pm SEM) c-fos expression (integrated density) across the rostral-caudal extent of the cingulate, a region of cortex that densely innervates the dorsomedial striatum. Squares represent cocainetreated groups and circles represent saline-treated groups. White symbols represent wild-type groups $(+/+)$ and black symbols represent ERKI mutant groups $(-/-)$. *, differs from the cocaine treated wild-type group $(p<0.05,2$ Way ANOVA, Bonferroni's test). $N=7-9 /$ group.

with drug-dependent behavioral plasticity (Pierce et al, 1999; Valjent et al, 2000; Mazzucchelli et al, 2002). In the present study we found that pharmacological blockade of ERK signaling attenuated the development of behavioral sensitization to cocaine, consistent with previous reports (Pierce et al, 1999; Valjent et al, 2005). In order to extend these findings, we next examined the role of specific ERK isoforms in some of the behavioral and neurobiological actions of cocaine. We found that deletion of ERK1: (1) facilitated the development of cocaine-induced behavioral sensitization; (2) facilitated the acquisition of a cocaine conditioned place preference; and (3) enhanced cocaineevoked c-fos expression in the striatum (ie nucleus accumbens and caudate-putamen) and the cingulate cortex. 
As previously described, ERK1 mutant mice are anatomically normal compared to their littermate controls and do not manifest any compensatory changes in basal expression of total ERK2 protein. However, these mice do show enhanced stimulus-dependent ERK2 signaling in the brain as well as in all tissues analyzed. Specifically in the brain, more ERK2 protein becomes phosphorylated in ERK1deficient mice following exposure to a glutamate or a dopamine D1 receptor agonist compared to wild-type controls (Mazzucchelli et al, 2002). These data suggest, therefore, that the facilitation of cocaine-evoked behavioral plasticity and IEG expression seen in the present study is most likely a consequence of increased ERK2 signaling following cocaine administration. In support of this idea, it has recently been reported that the administration of psychostimulant drugs produces a robust increase in phosphorylated ERK2 protein in the striatum (Valjent et al, 2005). The specific role of the ERK1 isoform in cocaine-mediated events appears more complex. We suggest that ERK1 normally serves to dampen ERK2 signaling, and drug exposure following suppression of ERK1 expression leads to heightened ERK2 signaling (Brambilla, 2003). Consistent with this hypothesis, we have found that the enhanced stimulus-dependent increases in ERK2 signaling seen in ERK1-deficient mice can be completely reversed in fibroblast cultures and primary neurons by either viral-mediated reintroduction of ERK1 protein or by administration of sub-optimal concentrations of a MEK inhibitor. Importantly, these treatments were also effective at reverting facilitation of LTP in the nucleus accumbens, one cellular correlate of drug-induced behavioral plasticity. Finally, overexpression of ERK1 but not ERK2 in wild-type cells has been found to downregulate overall ERK signaling output (Mazzucchelli et al, 2002; Vantaggiato et al, 2006).

To begin to explore the neurobiological processes by which ERK signaling may facilitate drug reward and psychomotor sensitization, we compared the responses of ERK1 mutant and wild-type mice to a single injection of cocaine. We found that the neurobiological impact of the same dose of cocaine was markedly different in mesocorticolimbic brain regions. Importantly, these effects cannot be attributed to mere differences in activity, as the acute locomotor activating effects of cocaine did not differ between groups. Specifically, cocaine increased gene expression in the cingulate cortex above control levels only when given to mice lacking the ERK1 isoform. Additionally, ERK1-deficient mice displayed a much more robust cocaine-evoked c-fos response in the striatum compared to wild-type mice. This effect in the caudate-putamen appears to be driven by the recruitment of striatopallidal neurons, which co-express mRNA for dopamine D2 receptors and preproenkephalin and project indirectly to the substantia nigra via the subthalamic nucleus to form the so-called 'indirect' pathway (Kawaguchi et al, 1990; Smith and Bolam, 1990; Smith et al, 1990). This result is consistent with a previous report that pharmacological blockade of the ERK signaling cascade preferentially attenuates psychostimulant-evoked c-fos expression in striatopallidal neurons (Ferguson and Robinson, 2004). Notably, the ability of drugs of abuse to engage this striatofugal circuit has been associated with the facilitation of psychomotor sensitization
(Samaha et al, 2005, 2004; Ferguson and Robinson, 2004; Samaha and Robinson, 2005). However, the relative signal intensity of each c-fos + cell was not examined in the present study, and therefore, it is possible that gene expression in striatonigral neurons was enhanced following cocaine administration in ERK1 mutant mice.

The functional significance of the changes in gene expression observed in the present experiments remains to be determined, however, activation of IEGs in mesocorticolimbic brain regions is thought to be one initial step in the induction of long-term changes in brain and behavior by drugs. In addition to behavioral plasticity, repeated cocaine treatment produces neurochemical (Di Chiara and Imperato, 1988), structural (Robinson and Kolb, 2004) and electrophysiological (Thomas et al, 2001; Borgland et al, 2004) alterations in mesocorticolimbic brain regions. These other forms of neural plasticity are all regulated by the Rascontrolled Raf-MEK-ERK protein kinase signaling cascade (English and Sweatt, 1996, 1997; see Impey et al, 1999; Wu et al, 2001; Mazzucchelli et al, 2002; Goldin and Segal, 2003; Thomas and Huganir, 2004 for review). Thus, it is possible that increased ERK2 signaling due to deletion of ERK1 engages neural circuits that facilitate the neuroadaptations associated with the rewarding and psychomotor sensitizing effects of cocaine. In support of this idea, one cellular correlate of psychomotor sensitization, synaptic plasticity in the nucleus accumbens, is enhanced in ERK1-deficient mice, as demonstrated by increased long-term potentiation following stimulation of cortical inputs (Mazzucchelli et al, 2002). As stated above, these changes in synaptic strength in the nucleus accumbens are directly linked to an increase in ERK2 activity since they can be fully rescued by treatment with a MEK inhibitor (Mazzucchelli et al, 2002). In addition, repeated cocaine exposure increases tyrosine hydroxylase (TH- the rate-limiting enzyme in dopamine synthesis) enzyme activity in the ventral tegmental area along with basal ERK catalytic activity (Vrana et al, 1993; Berhow et al, 1996). Given that blockade of the Raf-MEK-ERK signaling cascade decreases depolarization-induced phosphorylation of $\mathrm{TH}$ and subsequent accumulation of the dopamine precursor DOPA in striatal slices (Lindgren et al, 2002), these data suggest that ERK signaling may also regulate the neurochemical changes (eg augmented dopamine neurotransmission) associated with cocaine treatment. Nonetheless, given the complex interactions between the various signaling cascades, it is worth noting that there could be, as yet unidentified, compensatory changes in other signaling cascades that could contribute to the results seen in the present experiments. Future studies are necessitated to rule out these possibilities completely.

In conclusion, our findings demonstrate that mice that lack the ERK1 isoform, and consequently exhibit upregulation of stimulus-dependent ERK2 activity in the striatum, exhibit enhanced susceptibility to the rewarding and psychomotor sensitizing effects of cocaine. The neurobiological impact of cocaine, as indicated by an increase in cocaine-evoked c-fos expression, is also facilitated. Based on these observations, we propose that in the absence of ERK1, repeated exposure to cocaine leads to enhanced ERK2 signaling in the striatum, thus facilitating the development of enduring forms of drug-dependent behavioral plasticity and associated neuroplastic changes. Of note, similar 
patterns of ERK activation in brain have recently been observed for many commonly abused drugs (Valjent et al, 2004). In addition, the rewarding effects of morphine are also enhanced in ERK1-deficient mice (Mazzucchelli et al, 2002). It is likely, therefore, that altered ERK2 signaling in the mesocorticolimbic circuit represents part of a shared mechanism that mediates forms of drug-induced plasticity that may play a role in the development of addiction across drug classes.

\section{ACKNOWLEDGEMENTS}

This research was supported by a NIDA grant to TER (R37 DA04294), the Italian Ministry of University and Research (MIUR), the Mariani Foundation for Neurological Research and the Michael J Fox Foundation for Parkinson's Research to RB. TER was supported by a NIDA Senior Research Scientist Award (K05 DA00473) and SMF by a NIDA Individual NRSA (F31 DA14737).

\section{REFERENCES}

Adams D, Hanson GR, Keefe KA (2001). Psychostimulants activate $\mathrm{P} 42 / 44$ MAPK in dorsal and ventral striatum. Society Neurosci Abst 27: 445.2.

Adams JP, Sweatt JD (2002). Molecular psychology: roles for the ERK MAP kinase cascade in memory. Annu Rev Pharmacol Toxicol 42: 135-163.

Atkins CM, Selcher JC, Petraitis JJ, Trzaskos JM, Sweatt JD (1998). The MAPK cascade is required for mammalian associative learning. Nat Neurosci 1: 602-609.

Badiani A, Oates MM, Day HE, Watson SJ, Akil H, Robinson TE (1998). Amphetamine-induced behavior, dopamine release, and c-fos mRNA expression: modulation by environmental novelty. $J$ Neurosci 18: 10579-10593.

Berhow MT, Hiroi N, Nestler EJ (1996). Regulation of ERK (extracellular signal regulated kinase), part of the neurotrophin signal transduction cascade, in the rat mesolimbic dopamine system by chronic exposure to morphine or cocaine. J Neurosci 16: 4707-4715.

Berke JD, Hyman SE (2000). Addiction, dopamine, and the molecular mechanisms of memory. Neuron 25: 515-532.

Borgland SL, Malenka RC, Bonci A (2004). Acute and chronic cocaine-induced potentiation of synaptic strength in the ventral tegmental area: electrophysiological and behavioral correlates in individual rats. J Neurosci 24: 7482-7490.

Brambilla R (2003). Targeting Ras/ERK signaling in the striatum: will it help? Mol Psychiatry 8: 366-368.

Chao J, Nestler EJ (2004). Molecular neurobiology of drug addiction. Annu Rev Med 55: 113-132.

Choe ES, Chung KT, Mao L, Wang JQ (2002). Amphetamine increases phosphorylation of extracellular signal-regulated kinase and transcription factors in the rat striatum via group I metabotropic glutamate receptors. Neuropsychopharmacology 27: 565-575.

Choe ES, Wang JQ (2002). CaMKII regulates amphetamineinduced ERK1/2 phosphorylation in striatal neurons. Neuroreport 13: 1013-1016.

Curran EJ, Watson Jr SJ (1995). Dopamine receptor mRNA expression patterns by opioid peptide cells in the nucleus accumbens of the rat: a double in situ hybridization study. $J$ Comp Neurol 361: 57-76.

Di Chiara G, Imperato A (1988). Drugs abused by humans preferentially increase synaptic dopamine concentrations in the mesolimbic system of freely moving rats. Proc Natl Acad Sci 85: 5274-5278.

English JD, Sweatt JD (1996). Activation of p42 mitogen-activated protein kinase in hippocampal long term potentiation. J Biol Chem 271: 24329-24332.

English JD, Sweatt JD (1997). A requirement for the mitogenactivated protein kinase cascade in hippocampal long term potentiation. J Biol Chem 272: 19103-19106.

Everitt BJ, Dickinson A, Robbins TW (2001). The neuropsychological basis of addictive behaviour. Brain Res Brain Res Rev 36: 129-138.

Fasano S, Brambilla R (2002). Cellular mechanisms of striatumdependent behavioural plasticity and drug addiction. Curr Mol Med 2: 649-665.

Favata MF, Horiuchi KY, Manos EJ, Daulerio AJ, Stradley DA, Feeser WS et al (1998). Identification of a novel inhibitor of mitogenactivated protein kinase kinase. J Biol Chem 273: 18623-18632.

Ferguson SM, Robinson TE (2004). Amphetamine-evoked gene expression in striatopallidal neurons: regulation by corticostriatal afferents and the ERK/MAPK signaling cascade. J Neurochem 91: $337-348$

Gerdjikov TV, Ross GM, Beninger RJ (2004). Place preference induced by nucleus accumbens amphetamine is impaired by antagonists of ERK or p38 MAP kinases in rats. Behav Neurosci 118: 740-750.

Goldin M, Segal M (2003). Protein kinase C and ERK involvement in dendritic spine plasticity in cultured rodent hippocampal neurons. Eur J Neurosci 17: 2529-2539.

Hyman SE, Malenka RC (2001). Addiction and the brain: the neurobiology of compulsion and its persistence. Nat Rev Neurosci 2: 695-703.

Impey S, Obrietan K, Storm DR (1999). Making new connections: role of ERK/MAP kinase signaling in neuronal plasticity. Neuron 23: 11-14.

Kawaguchi Y, Wilson CJ, Emson PC (1990). Projection subtypes of rat neostriatal matrix cells revealed by intracellular injection of biocytin. J Neurosci 10: 3421-3438.

Lindgren N, Goiny M, Herrera-Marschitz M, Haycock JW, Hokfelt T, Fisone G (2002). Activation of extracellular signal-regulated kinases 1 and 2 by depolarization stimulates tyrosine hydroxylase phosphorylation and dopamine synthesis in rat brain. Eur J Neurosci 15: 769-773.

Maldonado R, Saiardi A, Valverde O, Samad TA, Roques BP, Borrelli E (1997). Absence of opiate rewarding effects in mice lacking dopamine D2 receptors. Nature 388: 586-589.

Martin KC, Michael D, Rose JC, Barad M, Casadio A, Zhu H et al (1997). MAP kinase translocates into the nucleus of the presynaptic cell and is required for long-term facilitation in Aplysia. Neuron 18: 899-912.

Mazzucchelli C, Vantaggiato C, Ciamei A, Fasano S, Pakhotin P, Krezel W et al (2002). Knockout of ERK1 MAP kinase enhances synaptic plasticity in the striatum and facilitates striatalmediated learning and memory. Neuron 34: 807-820.

McGeorge AJ, Faull RL (1989). The organization of the projection from the cerebral cortex to the striatum in the rat. Neuroscience 29: 503-537.

Nestler EJ (2001). Molecular basis of long-term plasticity underlying addiction. Nat Rev Neurosci 2: 119-128.

Orban PC, Chapman PF, Brambilla R (1999). Is the Ras-MAPK signalling pathway necessary for long-term memory formation? Trends Neurosci 22: 38-44.

Packard MG, Knowlton BJ (2002). Learning and memory functions of the basal ganglia. Annu Rev Neurosci 25: 563-593.

Pages G, Guerin S, Grall D, Bonino F, Smith A, Anjuere F et al (1999). Defective thymocyte maturation in p44 MAP kinase (Erk 1) knockout mice. Science 286: 1374-1377.

Paxinos G, Franklin K (2004). The Mouse Brain in Stereotaxic Coordinates, 2nd edn. Academic Press: San Diego. 
Pierce RC, Pierce-Bancroft AF, Prasad BM (1999). Neurotrophin-3 contributes to the initiation of behavioral sensitization to cocaine by activating the Ras/Mitogen-activated protein kinase signal transduction cascade. J Neurosci 19: 8685-8695.

Robinson TE, Berridge KC (1993). The neural basis of drug craving: an incentive-sensitization theory of addiction. Brain Res Brain Res Rev 18: 247-291.

Robinson TE, Berridge KC (2000). The psychology and neurobiology of addiction: an incentive-sensitization view. Addiction 95(Suppl 2): S91-S117.

Robinson TE, Kolb B (2004). Structural plasticity associated with exposure to drugs of abuse. Neuropharmacology 47(Suppl 1): 33-46.

Salzmann J, Marie-Claire C, Le Guen S, Roques BP, Noble F (2003). Importance of ERK activation in behavioral and biochemical effects induced by MDMA in mice. Br J Pharmacol 140: 831-838.

Samaha AN, Mallet N, Ferguson SM, Gonon F, Robinson TE (2004). The rate of cocaine administration alters gene regulation and behavioral plasticity: implications for addiction. J Neurosci 24: $6362-7370$.

Samaha AN, Robinson TE (2005). Why does the rapid delivery of drugs to the brain promote addiction? Trends Pharmacol Sci 26: 82-87.

Samaha AN, Yau WY, Yang P, Robinson TE (2005). Rapid delivery of nicotine promotes behavioral sensitization and alters its neurobiological impact. Biol Psychiatry 57: 351-360.

Schafe GE, Nadel NV, Sullivan GM, Harris A, LeDoux JE (1999). Memory consolidation for contextual and auditory fear conditioning is dependent on protein synthesis, PKA, and MAP kinase. Learn Mem 2: 97-110.

Selcher JC, Atkins CM, Trzaskos JM, Paylor R, Sweatt JD (1999). A necessity for MAP kinase activation in mammalian spatial learning. Learn Mem 6: 478-490.

Smith AD, Bolam JP (1990). The neural network of the basal ganglia as revealed by the study of synaptic connections of identified neurones. Trends Neurosci 13: 259-265.
Smith Y, Bolam JP, Von Krosigk M (1990). Topographical and synaptic organization of the GABA-containing pallidosubthalamic projection in the rat. Eur J Neurosci 2: 500-511.

Thomas GM, Huganir RL (2004). MAPK cascade signalling and synapic plasticity. Nat Rev Neurosci 5: 173-183.

Thomas MJ, Beurrier C, Bonci A, Malenka RC (2001). Long-term depression in the nucleus accumbens: a neural correlate of behavioral sensitization to cocaine. Nat Neurosci 4: 1217-1223.

Valjent E, Corvol JC, Pages C, Besson MJ, Maldonado R, Caboche (2000). Involvement of the extracellular signal-regulated kinase cascade for cocaine-rewarding properties. J Neurosci 20: 8701-8709.

Valjent E, Pages C, Herve D, Girault JA, Caboche J (2004). Addictive and non-addictive drugs induce distinct and specific patterns of ERK activation in mouse brain. Eur J Neurosci 19: $1826-1836$.

Valjent E, Pascoli V, Svenningsson P, Paul S, Enslen H, Corvol JC et al (2005). Regulation of a protein phosphatase cascade allows convergent dopamine and glutamate signals to activate ERK in the striatum. Proc Natl Acad Sci 102: 491-496.

Vantaggiato C, Formentini I, Costa M, Ratto GM, Bondanza A, Bonini C et al (2006). ERK1 MAPK acts as attenuator of Ras mediated cell growth and transformation. $J$ of Biology (in press).

Vrana SL, Vrana KE, Koves TR, Smith JE, Dworkin SI (1993). Chronic cocaine administration increases CNS tyrosine hydroxylase enzyme activity and mRNA levels and tryptophan hydrosylase enzyme activity levels. J Neurochem 61: 2262-2268.

Willuhn I, Sun W, Steiner H (2003). Topography of cocaineinduced gene regulation in the rat striatum: relationship to cortical inputs and role of behavioural context. Eur J Neurosci 17: 1053-1066.

Wu GY, Deisseroth K, Tsien RW (2001). Spaced stimuli stabilize MAPK pathway activation and its effects on dendritic morphology. Nat Neurosci 4: 151-158. 